\title{
Improving Crisis Exercises and Managers' Skills through the Development of Scenario Design
}

In this chapter, we will discuss the ways of improving the scripting phase of an exercise conception in order to improve crisis management training and experiential learning.

Attention should be given to the elaboration of scenarios, which is based on the scenario's central role in implementing, developing and even maintaining skills. More generally, it mainly contributes to the participants' immersion and involvement in the proposed exercise.

Thus, the scenario is both the heart and the skeleton of the exercise. It is therefore necessary to devote research and analysis to the development of the scenario, making it possible to ensure a rigorous and effective construction (ADPSA 2016), in agreement with the learning expectations and objectives of the participants.

\subsection{What is a pedagogical scenario for a crisis exercise?}

A scenario is a sequence of events that meets the training objectives. It corresponds to the planned sequence of events of the

Chapter written by Philippe Limousin, Aurélia BONY-DANDRIEUX, Jérôme TIXIER and Sophie SAUVAGNARGUES. 
exercise. Scriptwriting is the method of developing and organizing the stimuli that will compose the scenario.

The main purpose of an educational scenario is to develop the learners' skills in an optimal way. Thus, a learning situation must be set up and structured so that scriptwriting becomes pedagogical (Villiot-Leclercq 2006).

Regardless of the field using the exercise simulation for training (digital, military, medical, etc.), four main phases of educational scriptwriting are generally highlighted (Driskell and Johnston 1998, pp. 191-217; Department of Energy 2002; O'connor et al. 2002; DDSC 2005):

1) to identify training needs, including the review of lessons learnt from past crises and exercises;

2) to select the pedagogical objectives and define the scope and perimeter of the scenario;

3) to select and organize stimuli within the scenario to address the training objectives;

4) to assess and verify the scenario before its development through the execution of the exercise.

The first item should be completed by the identification of pre-existing skills in the group of participants, in particular, skills necessary to the tasks' execution, performed, for example, as part of emergency procedures (technical skills among others) and organizational skills, essential for teamwork required in crisis management.

\subsection{Why and for whom the script is crucial?}

The scenario is the central element for different actors of the training, namely participants (purpose of the exercise), animators who set the exercise to music and finally observers/evaluators (who are essential to ensure capitalization of skills acquired during the exercise) (El-Kechai 2008). 
The expectations of these different parties differ on how and what should constitute and compose the scenario (Figure 3.1).

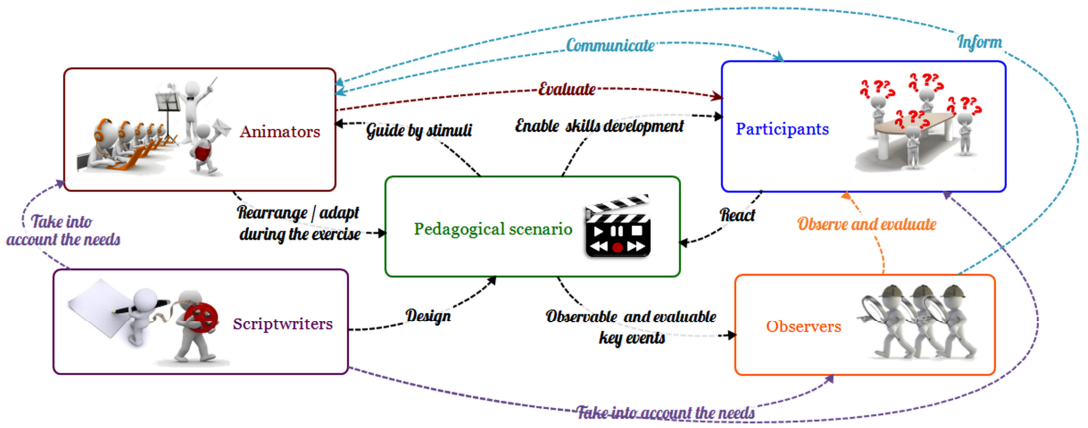

Figure 3.1. Stakeholders' expectations of the scenario. For a color version of this figure, see www.iste.co.uk/sauvagnargues/crisis.zip

\subsubsection{Stakes of scriptwriting for participants}

Exercise participants expect a coherent, plausible and credible scenario, but above all, they require that the exercise (and therefore the underlying scenario) enables them to implement or develop their skills (Gaultier-Gaillard et al. 2012). Furthermore, the scenario must not be too easy; otherwise, it may allow us to think that crisis management is only based on the easy implementation of procedures and that it will run smoothly.

The scenario must also not be too difficult and rigid (Combalbert 2005). The perverse effect could thus completely demobilize and demotivate the participants facing insurmountable to-do tasks and obstacles. This kind of exercise is completely counterproductive and presents no educational advantage.

\subsubsection{Stakes of scriptwriting for animators}

Concerning animators, the scenario is a guide or framework essential to the development of the exercise. It allows them to inject stimuli at appropriate times during the exercise and to relevant persons. 
Moreover, the scenario provides a backdrop to which they can refer in order to react more easily to the participants' answers during the exercise (IRM 2008).

The understanding of the scenario and the implementation by animators are fundamental to ensure the success of the crisis exercise and thus promote participants immersion, their interest in the exercise and therefore their learning.

\subsubsection{Stakes of scriptwriting for observers}

Finally, for observers, two different points of view can be adopted. The first one is based on the total ignorance of the exercise scenario that will be observed. This ensures a very high neutrality in the apprehension of the actions and interactions established between the participants. Conversely, the second considers the scenario as a framework of events, requesting specific reactions and thereby identifying key elements to be observed and evaluated. In this second approach, the scenario construction phase and the creation of observation tools fuel each other (Lapierre 2016).

\subsection{How can we improve the pedagogical scripting of crisis exercises?}

The implementation of several existing scriptwriting methods (Cohen et al. 1998; Fowlkes et al. 1998; DSC 2009; Fagel 2014, p. 502; Heiderich and Maroun 2017) has brought to light that they are not directly operational. It has also made it possible to identify several weaknesses and limitations. For example, there is no exhaustive list of training objectives for a crisis exercise.

Moreover, the scriptwriter is not guided in the choice of events to be inserted in the scenario in order to solicit the desired skills or to recreate a crisis universe.

Indeed, the scenarios must be as close as possible to reality in the transcription of a crisis situation, in particular, concerning the inclusion of the stress factor (Gaultier-Gaillard et al. 2012). 
The lack of crisis characteristic elements in the exercise scenarios (Robert 2002; Combalbert and Delbecque 2012, p. 128; Lagadec 2015; Heiderich and Maroun 2017) justifies the development and improvement of this exercise design stage.

Thus, a scriptwriter faces many difficulties and questions:

- How should a training scenario adapted to the participants be designed? This led us to question (i) the methods for evaluating the level of participants prior to the exercise, (ii) the objectives of scriptwriting, (iii) transforming the pedagogical intentions into stimuli and (iv) the quantity of stimuli to inject into the scenario.

- How can the specific crisis features be replicated in the scenarios? In other words, what stimuli can be used to recreate uncertainty, surprise, etc. and how often should they be inserted into the scenarios in order to reproduce a crisis dynamic?

- How should the scenarios be verified and validated once created, in terms of coherence, difficulty or relevance, particularly concerning the solicitation of learners' skills?

Currently, it is difficult for a scriptwriter to handle all the constraints imposed on crisis exercise scenarios (believable, credible, adapted to the level and skills of the participants, etc.). It is therefore necessary to improve existing methods and tools in order to help the scriptwriter and to contribute to improving crisis management training.

The abovementioned difficulties led us to draw up a list of ways to improve the pedagogical scenario of crisis exercises. Several themes have therefore been identified:

- scripting steps to improve (i) the consideration of participants' characteristics and (ii) the distribution of stimuli in the scenario;

- scriptwriting objectives, in particular, to list pedagogical intentions and define a scenario framework to be respected;

- the links between stimuli and objectives in order to propose to the scriptwriters a method and means to insert learning levers associated with specific skills; 
- an evaluation phase of the scenario to contribute to its verification before the development phase.

These four themes have been studied and are addressed in the following sections. It is important to note that our results are based on an iterative process of testing and improvement of the scripting stage since many exercises have been implemented within the simulation facility of IMT Mines Alès or directly within crisis units from administrations or industries.

\subsection{Methodology to develop a crisis exercise scenario}

The methodology is built on the four main phases of pedagogical scriptwriting. It is necessary to detail them before proposing specific means to make them more operational. First, regardless of the considered step, scriptwriters must always keep in mind for whom, why and how they write.

The scenario created will not necessarily concern all the risks capable of impacting the company or the city. The aim is not to ensure that crisis teams know all conceivable scenarios (which is quite impossible), but that they know how to behave in the face of different situations that may happen. Furthermore, it is necessary to define specific objectives to the participants, their crisis organization and group level.

However, one of the main barriers is the heterogeneity of participants' level within the group, whether this refers to the variable level of knowledge on crisis management of participants, to the individual or collective experience specific to each individual, to the skills and therefore training needs and ultimately to the pedagogical objectives of each person.

Nevertheless, to facilitate scriptwriting, it is possible in a first simplification step to classify the group of participants as either a novice, competent or an expert according to several criteria (experience, knowledge of the territory, etc.). 
In addition, scriptwriters must meet specific objectives, particularly in terms of training and reproduction of a crisis situation.

\subsubsection{Prepare the scriptwriting}

Scriptwriting begins by meeting the organization's head of crisis management training and the main stakeholders (participants). The first meeting will enable the scriptwriters to identify and characterize the participants of the exercise and define, with them, the operational and crisis objectives (see section 3.4.2). The duration of the scenario and its perimeter are often defined during this first meeting. Scriptwriters must continue this meeting process during scriptwriting (Borglund and Öberg 2014) in order to mobilize and involve different stakeholders and validate the consistency of the script. By knowing the main events of the scenario, the participating crisis organization can prepare and improve its crisis management before the exercise.

Scriptwriting should not be the prerogative of the scriptwriter alone, since the development of crisis management resources and stakeholder awareness often takes place during this stage. However, it is necessary not to give information to the participants about the scenario (in particular, for an unannounced exercise or for an exercise including a confidential scenario).

Moreover, in many cases, improving the deep understanding of the functioning and the experiences of the crisis organization is an important criterion for the scenario's success.

Finally, it can be relevant for the scriptwriters to establish a mapping of stakeholders from the organization to broaden the scope of the scenario.

\subsubsection{Better define the objectives to achieve}

Scriptwriting starts by identifying key objectives for the exercise (Heiderich 2010). 
Thus, three categories of objectives were defined in order to produce a pedagogical scenario dedicated to crisis exercises (Limousin 2017):

\section{Operational objectives (technical or organizational)}

They correspond to the expected actions from the participants which will have to be requested by the scenario. For example, an operational objective may be to achieve a situation update, to determine the hazardous phenomenon or to identify threatened issues. These objectives must be identified and selected in a judicious way.

The analysis of several past crises, of various crisis exercises' reviews, of job descriptions and crisis procedures of several crisis team members from different organizations have allowed us to identify nearly 150 operational objectives.

The solicitation of one or several of these objectives by injecting stimuli in the scenario will require that the participants implement specific skills.

When preparing the exercise, it is essential to match these objectives with the function, role, responsibilities, skills (technical and organizational) and needs of participants.

\section{Crisis objectives}

This family of objectives aims at offering help to the scriptwriter to reproduce the characteristics of a crisis universe in the scenarios. These objectives correspond in particular to the insertion of ambiguous and uncertain elements, surprise, stress, temporal pressure or wrong tracks (as many elements producing a wide range of emotion and feelings of imminent hazard). Thus, 12 crisis objectives are suggested for the scriptwriting of crisis exercises (Limousin 2017).

\section{Objectives of the pedagogical framework}

These objectives represent the creation of a learning situation. In our research work, seven pedagogical framework's objectives have 
been defined (Limousin 2017): to be coherent and credible, to be relevant, to adapt to the level of the participants, to maintain an appropriate level of involvement, to be a challenge, to keep the participants in suspense and to be immersive.

The definition of these objectives will provide a framework for the scriptwriter in the verification phase and enable him/her to ensure that he/she has met the objectives of the pedagogical scriptwriting for the crisis exercise.

\subsubsection{Develop the crisis scene and construct the initial spatio-temporal structure of the scenario}

This stage corresponds to the definition phase of the scenario scope, in particular, by identifying the stakes and hazardous phenomena. The scriptwriter may rely on this initial crisis scene for the development of their script and the insertion of learning levers.

Generally speaking, a scenario begins with the occurrence of an important, major event or its announcement (crisis triggering or revealing phenomenon) followed by a sequence of events (Rankin et al. 2011, p. 22).

Above all, it is important to identify the number of phenomena and issues adapted to the profile of the participants. We assumed that it was possible to define these quantities on the basis of the analysis of the exercises carried out, observed and evaluated. Consequently, we proposed to inject five to seven phenomena for a three-hour exercise to train experienced learners. This value includes the main phenomena (e.g. floods), precursor phenomena (e.g. runoff), reinforcing phenomena (e.g. wind) or cascading events (e.g. floods) and even independent phenomena.

The value of this parameter is integrated in the calculation of the scenario's difficulty level. Nevertheless, the characteristics of the phenomena and their issues also influence the difficulty index of the scenario. Thus, it is necessary to compare the profile of the 
participants with the "impact scores" of phenomena and issues (result relative to the evaluation of the impact of the elements on the level of difficulty of the scenario).

Once the number and impact score of phenomena and stakes are in mind, the scriptwriter selects those adapted for the exercise according to (i) the wishes or regulatory obligations of the organization's crisis management training manager, (ii) the profile of the participants, (iii) objectives, (iv) potential animators, (v) the presence or absence of a description of the elements in the contingency plans and (vi) the duration of the scenario. It is then necessary to organize the occurrence of events in the scenario in such a way as to increase the level of difficulty and suspense over time. Once the crisis scene is created, the next step consists of inserting learning levers to solicit all the selected objectives.

\subsubsection{Insert learning levers to solicit training objectives: the obstacles}

The methods for crisis exercises' scriptwriting encourage scriptwriters to insert events related to the selected objectives (Fowlkes et al. 1998; FEMA 2017). Nevertheless, it is necessary to define the method for identifying these events and their relationship with the objectives.

The skills of the participants in crisis management must be requested during the exercise through the upstream inclusion of learning levers in the scenario. The CTT method (Cohen et al. 1998) uses events that put learners in a degraded situation. In addition, in the artistic field, scriptwriters use conflicts and obstacles to develop their scenario (Lavandier 2014). Thus, based on these methods, we can advise crisis exercise scriptwriters to insert specific obstacles in their scenario to solicit the selected objectives. These obstacles must disrupt the management of the situation and, consequently, ask participants to implement actions associated with the requested objective. Thus, scriptwriters must question the obstacles that would require 
specific actions to be taken or that would oppose a good execution of situation management. Scriptwriters can use past crises, identified deficiencies of the participating crisis organization and past exercises on the same theme to identify challenges to be included in the scenario.

These considerations led to the creation of a non-exhaustive database of goal-related barrier stimuli (Limousin 2017).

For example:

- if the objective is to test the setting up of a safety perimeter around an accident, then the animators can inform the participants of the presence of many onlookers who may hinder and slower the arrival of emergency services;

- if the objective aims at testing the management of the crisis unit, scriptwriters can insert dilemmas in the scenario. A concrete example is the injection of a message involving the choice between two decisions, implying serious but different losses for each one.

In short, by inserting obstacles, the pedagogical objective is indirectly called and requires participants' initiative. In addition, observation is facilitated because the scriptwriter can propose to the observers to evaluate their capacity to cross an obstacle.

\subsubsection{Insert stimuli to not solicit unselected objectives: support stimuli}

Our research work has led to the definition of "support stimuli". They are designed to help participants when a solicitation asks for the implementation of unselected objectives. Indeed, it proved relevant not to make the participants work on actions that they master and to focus their attention instead on the skills to be tested or improved. Thus, the method (Limousin 2017) suggests injecting support stimuli in the scenario to not work on unselected objectives. To identify the support stimuli of the script, the scriptwriter must find the best way to help participants or to avoid them working on an unselected goal. 


\subsubsection{Adjust the number of stimuli to the level and objectives of the participants}

However, the number of obstacles must be limited according to the profile of the participants, in order to maintain their involvement.

The challenge for the scriptwriter includes finding a good compromise in the scenario's difficulty in order to maintain attractiveness to participants of the crisis exercise and to optimize learning (Cook 2006).

As already mentioned, a highly stimulating scenario may frighten and can seriously inhibit participants, creating, for example, discomfort or even strong anxiety, therefore restricting learning. Conversely, an easier scenario can prevent participants' demobilization but if the scenario is too easy, learning becomes poor (FEMA 2017).

It is therefore necessary to adapt the level of difficulty of the scenario to that of the participants.

Thus, we proposed to limit the number of operational objectives to be selected according to the duration of the exercise and the profile of the participants (e.g. between 5 and 10 operational objectives per hour for experienced ones) (Limousin 2017).

Furthermore, the scenario is scalable during the exercise, and animators must have the instinct to adapt in real time, according to the reaction capability of participants, the number of stimuli upward or downward.

\subsubsection{Recreate a crisis universe: crisis stimuli}

"A crisis simulation has as its major goal to recreate a sufficiently uncertain universe" (Heiderich and Maroun 2017). Indeed, a few years ago, the scenarios were only just operational; today, one aims to write scenarios which are as real as possible in order to reproduce a crisis situation. 
Defining crisis objectives for exercises is thus a step forward. Nevertheless, it is necessary to provide reliable support to the scriptwriter in order to insert the characteristics of a crisis into the scenarios.

Crisis stimuli can be based on lessons learnt from past crises to identify the types and kinetics of the events that crisis managers have faced. These events, their characteristics and frequency could be inserted in crisis exercises. It is also relevant to pay attention to the methods used in the artistic field (Cotte 2014; Lavandier 2014) to inject these types of characteristics into the film or theater scenarios.

Therefore, it is necessary to analyze the cause of surprise, uncertainty, ambiguity, wrong tracks, breakdowns, disturbances or stress in order to reproduce them in the scenarios. When the cause is identified, it becomes easy for the writer to insert the characteristics of a crisis. For example, sources of ambiguity may emerge:

- at the informational level: the information given by the services or by data acquisition systems, the mass of information, the language being used;

- from misunderstanding stakeholders' functions, goals, coordination or behavior;

- at the situation level: ignorance or misunderstanding of facts, expectations, potential developments.

More specifically, if the scriptwriter wishes to insert ambiguity at the informational level, they can insert two opposite or different pieces of information which are both legitimate (e.g. the results of two calculation models).

As for objectives, the number and quality of crises' stimuli must be limited with regard to the profile of the participants. Thus, after inserting all the stimuli, the scriptwriter must check several parameters and validation criteria of the created scenario. 


\subsubsection{Verify and validate the pedagogical scriptwriting}

In order to verify educational scriptwriting, the scriptwriter must consider several components of the script:

- its structure: the coherence between events (Bernard 2014) (logic and time dependence, for example); potential omissions and the sequence of stimuli must be examined;

- its credibility: will the participants consider the events as credible? If the answer is no, why and what may be modified?

- its level of difficulty and dynamics: this corresponds to the impact scores over time of the issues, phenomena and all the stimuli that address the objectives;

- its staging and immersion: can the scenario be fictitiously implemented during the exercise (e.g. dummies to simulate victims)?

- involvement of participants: are all participants regularly involved in the exercise?

The training manager of the participating crisis organization or other third parties should also verify the scenario (Borglund and Öberg 2014). When the script is verified, scriptwriters should explain it to animators and observers.

\subsubsection{Prepare the scenario for animators and observers}

In this last stage of scripting, it is necessary to translate the events in such a way that they can be directly transmitted by the animators during the exercise and correctly solicit the targeted objectives. In addition, it is also relevant to propose to the animators a list of recall/redundant stimuli if the trainers want to implicitly request an unattained objective for a second time (Dieudonné and Poumay 2008).

This action will help to define answers to questions that participants may ask during the training. However, animators will need an evaluation during the exercise to determine if the objective has been met. It is therefore necessary to present the scenario to observers well in advance of the exercise so that they can establish 
performance criteria for overcoming obstacles related to the objectives. They will thus be able to focus their attention on the receivers of the stimulus when it appears. As a result, observers will be able to advise the animators whether it is necessary to further solicit the objective. In addition, observers can provide a relevant look at the stimuli of the script and, in agreement with the scriptwriters, modify the stimuli in order to make a better evaluation.

\subsection{Conclusion}

A crisis exercise scenario corresponds to the description of the events facing which the participants will have to react to, will be trained for and evaluated on. A pedagogical scenario must solicit targeted training objectives and be able to be adaptable in real time according to the reactions and responses of participants.

The research we have carried out on challenges concerning pedagogical scriptwriting has succeeded in removing certain difficulties for the scriptwriter and ensuring the development of crisis units' skills.

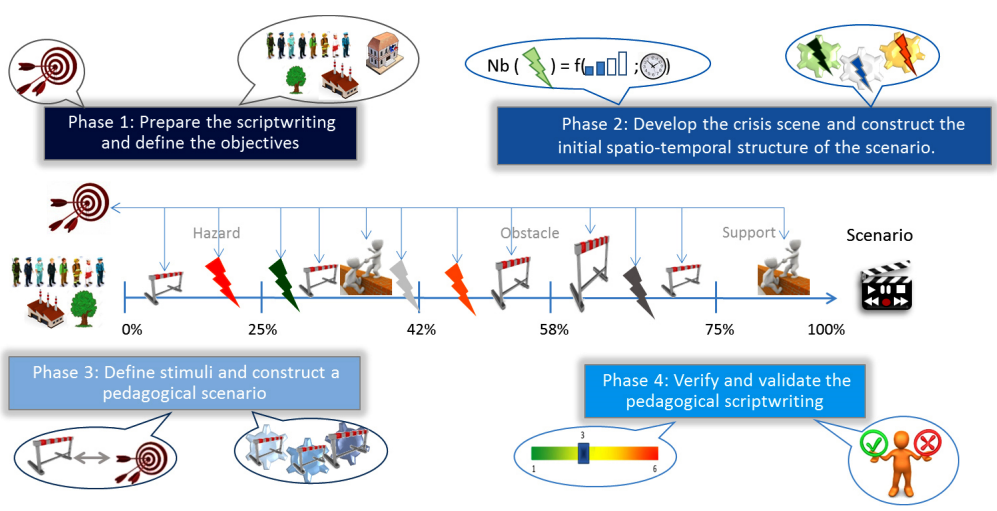

Figure 3.2. The stages of scriptwriting with the representation of a pedagogical scenario. For a color version of this figure, see www.iste.co.uk/sauvagnargues/crisis.zip 
Indeed, we have identified stages of pedagogical scriptwriting for crisis exercises and defined several specific tools for the scriptwriter as criteria for evaluating the scenario (Figure 3.2). Our research work has therefore led to the definition of several stimuli: stimuli soliciting operational objectives, crises, redundant stimuli and support stimuli.

This research may therefore contribute to improving training in crisis management through the enrichment of methods and means for pedagogical scriptwriting.

However, there is a need for more research and development, both considering further development of the scenario and the evaluation of the design process (Borglund and Öberg 2014). It is also possible to improve the organization (quantity and occurrence) of stimuli within the scenario in order to develop its structure and get closer to a crisis dynamic.

\subsection{References}

ADPSA (2016). Guide pratique pour rédiger un scénario pédagogique. Available: http://www.adpsa12.org/ADPSA_modele/DOC_PDF/DI_Guid e_Pratique_scenario_pedagogique.pdf [Accessed 11 January 2016].

Bernard, L. (2014). Guide pratique de formation par la simulation. VA Press, Versailles.

Borglund, E.A.M. and Öberg, L.-M. (2014). Creation of an exercise scenario: a collaborative design effort. Proceedings of the 11th International ISCRAM Conference, May, 488-492.

Cohen, M.S., Freeman, J.T., and Thompson, B. (1998). Critical thinking skills in tactical decision making: a model and a training strategy. In Decision-Making Under Stress: Implications for Training \& Simulation, Canon-Bowers, J. and Salas, E. (eds). American Psychological Association Publications, Washington, DC. 
Cook, D. (2006). Safety and training. Free flight - The Journal of the Soaring Association of Canada, 3(6), 16-17.

Combalbert, L. (2005). Le Management des situations de crise. Anticiper les risques et gérer les crises. ESF éditeur, Paris.

Combalbert, L. and Delbecque, É. (2012). La gestion de crise. PUF, Paris.

Cotte, O. (2014). Écrire pour le cinéma et la télévision. Structure du scénario, outils et nouvelles techniques d'écriture créative. Dunod, Paris.

Dieudonné, L. and Poumay, M. (2008). Le Modèle des Evénements d'Apprentissage - Enseignement, LabSET-IFR.

Direction de la Défense et de la Sécurité Civiles (2005). Plan Communal de Sauvegarde: Guide pratique d'élaboration. Ministère de l'intérieur et de l'aménagement du territoire.

Direction de la Sécurité Civile (2009). Exercices de Sécurité Civile: Guide thématique sur les exercices PPI. Ministère de l'intérieur, de l'outre-mer et des collectivités territoriales, p. 80.

Driskell, J.E. and Johnston, J.H. (1998). Stress exposure training. In Making Decisions Under Stress: Implications for Individual and Team Training, Cannon-Bowers J.A. and Salas E. (eds). American Psychological Association, Washington, DC.

El-Kechai, H. (2008). Conception Collective de scénarios pédagogiques dans un contexte de réingénierie : une approche par la métamodélisation située. Informatique [cs]. University of Maine, France. Available: https://tel.archives-ouvertes.fr/tel-00343203/document.

Fagel, M.J. (2014). Crisis Management and Emergency Planning: Preparing for Today's Challenges. CRC Press Taylor and Francis Group.

Federal Emergency Management Agency (2017). Course: IS-120.a - An Introduction to Exercises Lesson 4: Design and Development. Available: https://emilms.fema.gov/IS120A/module4.htm [Accessed 20 December 2017].

Fowlkes, J., Dwyer, D.J., Oser, R.L. and Salas, E. (1998). Event-based approach to training (EBAT). Int. J. Aviat. Psychol., 8(3), 209-222. 
Gaultier-Gaillard, S., Persin, M. and Vraie, B. (2012). Gestion de crise - Les exercices de simulation: de l'apprentissage à l'alerte. AFNOR, La Plaine Saint-Denis.

Heiderich, D. (2010). Plan de gestion de crise: organiser, gérer et communiquer en situation de crise. Dunod, Paris.

Heiderich, D. and Maroun, N. (2017). La mise en récit des exercices de crise. Article de fond dans la LIREC, Newsletter, l'Institut national des hautes études de la sécurité et de la justice (INHESJ), July 2017.

Institut des Risques Majeurs (2008). Mémento Exercices Plan Communal de Sauvegarde. Grenoble.

Lagadec, P. (2015). Le continent des imprévus - Journal de bord des temps chaotiques. Les Belles Lettres, Paris.

Lapierre, D. (2016). Méthode EVADE: Une approche intégrée pour l'EValuation et l'Aide au DEbriefing. University of Nîmes, France. Available: https://tel.archives-ouvertes.fr/tel-01695574/document

Lavandier, Y. (2014). La dramaturgie, l'art du récit. Le Clown \& L’enfant.

Limousin, P. (2017). Contribution à la scénarisation pédagogique d'exercices de crise. PhD Thesis, University of Lyon, L'École des Mines de Saint-Etienne.

O’connor, P., Hörmann, H., Flin, R., Lodge, M. and Goeters, K.M. (2002). The U.S. Navy's Crew Resource Management program: The past present, and recommendations for the future. Int. J. Aviat. Psychol., 12(3), 263-286.

Rankin, A., Kovordanyi, R., Field, J.N., Morin, M., Jenvald, J. and Erikson, H. (eds) (2011). A scenario-based modelling method for simulation systems. In Proceedings of ISCRAM 2011, May 8-11, Lisbon, Portugal.

Robert, B. (2002). Nouvelles pratiques pour le pilotage des situations de crise: dix ruptures pour passer d'une logique de procédures à l'apprentissage de la surprise. Environnement, Risques \& Santé, $1(1), 22-30$. 
Department of Energy Office of Transportation and Emergency Management (2002). Guidance for Planning, Conducting and Evaluating Transportation Emergency Preparedness Tabletops, Drills and Exercises. Prepared for the Department of Energy Office of Transportation and Emergency Management, p. 46. Available: $\quad$ https://www.energy.gov/sites/prod/files/em/TEPP/4-a1GuidanceforPlanningExercises.pdf

Villiot-Leclercq, E. (2006). Capitaliser, diffuser, réutiliser l'expertise pédagogique pour la conception de scénarios pédagogiques: des outils et des méthodes pour enrichir les pratiques dans un contexte d'enseignement à distance [Online]. Available: https://edutice.archives-ouvertes.fr/edutice-00001416v1/document 
1 